\title{
Effects of Androgen Deprivation Therapy on Pain Perception, Quality-of-Life and Depression in Men with Prostate Cancer
}

\author{
Thiago Gagliano-Jucá ${ }^{1}$, Thomas G. Travison ${ }^{2}$, Paul L. Nguyen ${ }^{3}$, Philip W. Kantoff ${ }^{4}$, Mary- \\ Ellen Taplin ${ }^{5}$, Adam S. Kibel ${ }^{6}$, Robert Manley ${ }^{1}$, Kathleen Hally ${ }^{1}$, Richelle Bearup ${ }^{1}$, Yusnie M. \\ Beleva $^{1}$, Grace Huang ${ }^{1}$, Robert R. Edwards ${ }^{7}$, and Shehzad Basaria ${ }^{1}$ \\ ${ }^{1}$ Research Program in Men's Health: Aging and Metabolism, Brigham and Women's Hospital, \\ Harvard Medical School, Boston, MA \\ ${ }^{2}$ Program on Aging, Hebrew SeniorLife, Roslindale, MA \\ ${ }^{3}$ Department of Radiation Oncology, Dana Farber Cancer Institute, MA \\ ${ }^{4}$ Departments of Medicine, Memorial Sloan Kettering Cancer Center and Weill Cornell Medical \\ College, New York, NY \\ ${ }^{5}$ Department of Medical Oncology, Dana Farber Cancer Institute, MA \\ ${ }^{6}$ Division of Urology, Brigham and Women's Hospital, Harvard Medical School, Boston, MA \\ ${ }^{7}$ Department of Anesthesiology, Brigham and Women's Hospital, Harvard Medical School, \\ Boston, MA
}

\begin{abstract}
Context-Previous animal and human research suggests that testosterone has anti-nociceptive properties. Castration in male rodents increases pain perception which is reversed by testosterone replacement. Pain perception also improves in hypogonadal men with testosterone therapy. However, it remains unclear whether androgen deprivation therapy (ADT) in men with prostate cancer $(\mathrm{PCa})$ is associated with an increase in pain perception.

Methods-Thirty-seven men with PCa about to undergo ADT with leuprolide acetate (ADT group) were followed prospectively for 6 months to evaluate changes in clinical and experimental pain. Forty men who had previously undergone prostatectomy for localized PCa and were in remission served as controls (Non-ADT Group). All participants were eugonadal at study entry. Primary outcomes were changes in clinical pain (assessed with brief pain inventory questionnaire)
\end{abstract}

Corresponding Author: Shehzad Basaria, M.D., Research Program in Men's Health: Aging and Metabolism, Brigham and Women's Hospital, Harvard Medical School, 221 Longwood Ave, BLI-541, Boston, MA 02115., Phone: +1 617-525-9150, Fax: +1 617-525-9148, sbasaria@partners.org.

Disclosure statement: Dr. Basaria has previously received grant support from Abbott Pharmaceuticals for investigator-initiated studies unrelated to this study and has previously consulted for Eli Lilly, Inc and Regeneron Pharmaceuticals. Dr. Nguyen has consulted for Ferring, Medivation, Bayer and Astellas, and receives research funding from Astellas and Janssen. Dr. Kibel consults for Janssen, MDxHealth and Profound. Other authors have reported no conflicts.

Publisher's Disclaimer: This is a PDF file of an unedited manuscript that has been accepted for publication. As a service to our customers we are providing this early version of the manuscript. The manuscript will undergo copyediting, typesetting, and review of the resulting proof before it is published in its final citable form. Please note that during the production process errors may be discovered which could affect the content, and all legal disclaimers that apply to the journal pertain. 
and experimental pain (assessed with quantitative sensory testing). Secondary outcomes included evaluation of depression, anxiety levels and quality of life (QOL).

Results-Serum testosterone levels significantly decreased in the ADT group but remained unchanged in the Non-ADT group. There were no significant changes in pain thresholds, ratings, or other responses to quantitative sensory tests over the 6-month course of the study. Clinical pain did not differ between the two groups, and no changes from baseline were observed in either group. Men undergoing ADT did experience worsening of depression $(0.93 ; 95 \% \mathrm{CI}=0.04$ to 1.82 ; $\mathrm{p}=0.042)$, and QOL related to physical role limitation $(-18.28 ; 95 \% \mathrm{CI}=-30.18$ to -6.37 ; $\mathrm{p}=0.003)$.

Conclusion-ADT in men with $\mathrm{PCa}$ is associated with worsening of depression scores and QOL, but is not associated with changes in clinical pain or pain sensitivity.

\section{Key Terms}

Prostate Cancer; GnRH agonists; testosterone; quantitative sensory testing; pain perception; pain tolerance; quality of life; depression

\section{Introduction}

Substantial body of animal research across a number of species has shown that testosterone has anti-nociceptive properties and that it modulates sensitivity to pain. ${ }^{1,2}$ Castration of male rodents is associated with increased sensitivity to pain while testosterone administration in these castrated animals provides greater analgesia in response to noxious stimuli. ${ }^{3}$ This improvement in analgesia is across a variety of noxious stimuli, including thermal, mechanical and pressure stimuli. There is also abundant evidence that women and men do not experience pain equally. ${ }^{4}$ Large-scale epidemiological studies find that both acute and chronic pain conditions are reported more frequently by women than men. ${ }^{5-7}$ Women are also at a greater risk for developing chronic widespread pain, which is estimated to affect $10-15 \%$ of the population. ${ }^{8}$ In addition to reporting clinical pain, women also exhibit greater sensitivity to experimental pain and perceive standardized painful stimuli as more intense than men including mechanical, electrical, thermal and chemical stimuli across body sites. ${ }^{9}$ These data suggests that testosterone enhances the potency of endogenous opioids in men.

In addition to these clinical reports, functional neuroimaging studies further confirm differential nociceptive processing among men and women. ${ }^{10}$ Imaging studies reveal that endogenous serum testosterone levels are positively correlated with the activation of the rostral ventromedial medullary area which enhances the activity of descending pain inhibitory pathways. ${ }^{11}$ Furthermore, randomized placebo-controlled clinical trials in hypogonadal men with chronic pain show that testosterone replacement is associated with improvement in clinical pain, experimental pain and health-related quality of life (QOL), ${ }^{12}$ further confirming that testosterone has anti-nociceptive properties.

Prostate cancer (PCa) is the most common solid cancer in American men. ${ }^{13}, 14$ As prostate is an androgen-dependent tissue, androgen deprivation therapy (ADT) is used in men with locally advanced, recurrent and metastatic disease. ${ }^{15-17}$ The goal of ADT is to suppress 
testosterone production, lowering it into the castrate range $(<50 \mathrm{ng} / \mathrm{dL}) .{ }^{18}$ As a result, men undergoing ADT experience profound androgen deficiency which is associated with a number of adverse effects that include sexual dysfunction, osteoporosis, vasomotor symptoms, metabolic syndrome and reduced QOL. ${ }^{19-21}$ Since sex steroids play an important role in pain physiology, the profound androgen deficiency that occurs as a result of ADT might also have a detrimental impact on pain perception in these patients. This is particularly relevant as patients with cancer have a high prevalence of pain even in the absence of metastatic disease. ${ }^{22-24}$ Furthermore, evaluation of men undergoing ADT provides an ideal opportunity to determine the anti-nociceptive role of testosterone.

The Androgen Deprivation Therapy and Pain Perception (ADT and Pain) Study was a prospective observational cohort study that evaluated clinical and experimental pain in men with non-metastatic PCa undergoing ADT and compared them to men with localized PCa who had previously undergone prostatectomy and were in remission.

\section{Methods}

\section{Study Design and Participants}

The ADT and Pain study was a prospective observational cohort study to evaluate changes in pain perception and tolerance in men undergoing ADT for PCa. Thirty-seven men about to undergo medical ADT with GnRH agonist [22.5 mg of leuprolide acetate (Lupron depot; TAP Pharmaceuticals)] every 3 months with a planned intervention of at least 6 months were enrolled from the Dana Farber Cancer Institute (ADT group). These men also received an androgen receptor antagonist (bicalutamide) during the first month of treatment to prevent tumor flare. Additionally, 40 men with PCa who had undergone prostatectomy and/or radiation therapy for organ-confined $\mathrm{PCa}$ at least 6 months prior to enrollment and were in remission were also enrolled and served as the control group and were recruited from the Brigham and Women's Hospital (Non-ADT group). All men had normal serum total testosterone concentrations at the time of enrollment and did not have any chronic pain condition. Other exclusion criteria included surgical ADT, skeletal metastasis, use of opioidanalgesics, peripheral neuropathy, painful inflammatory conditions, use of glucocorticoids, diabetes, and moderate to severe depression as assessed by the Patient Health Questionnaire (PHQ-9). ${ }^{25}$

The study protocol was approved by the institutional review board at the Dana Farber Cancer Institute, Boston, Massachusetts. Enrollment took place between July 2013 and April 2016; the last participant completed the study in November 2016. All participants provided written informed consent.

\section{Primary Outcomes}

The primary outcomes were the change in self-reported pain as assessed by the Brief Pain Inventory (BPI) questionnaire, and experimental pain as assessed by quantitative sensory testing (QST). All assessments were performed at baseline and then 6-weeks, 3-months and 6-months into ADT (ADT group). For the Non-ADT group, assessments were performed at baseline and then 6-weeks, 3-months and 6-months after enrollment. 
Brief Pain Inventory Questionnaire-The BPI is a validated questionnaire that evaluates pain severity by asking subjects to rate their current pain as well as their worst, least, and average pain over the past day. ${ }^{26-28}$ The questionnaire also assesses pain interference in patient's lives, with subjects rating how much pain interfered with their general activity, mood, mobility, work activities, social life, sleep, and enjoyment of life. $26-28$

Quantitative Sensory Testing (QST)—QST was performed by using validated tests $^{29-32}$ in the pain laboratory to assess sensitivity to calibrated mechanical and thermal (cold) noxious stimuli while the subjects sat comfortably in a reclining chair. The details of these procedures are described below.

Pressure Pain: Pressure pain thresholds (PPTh) were assessed using a digital pressure algometer (Somedic, Horby, Sweden) at the trapezius muscle and the metacarpophalangeal joint of the thumb. At each site, mechanical force was applied using a $0.5 \mathrm{~cm}^{2}$ probe; pressure was increased at a steady rate of $30 \mathrm{kPa} / \mathrm{s}$ until the subject indicated that pressure was "first perceived as painful". 29,30

Reaction to prolonged pressure pain was ascertained by cuff pressure algometry. Tonic, deep-tissue mechanical stimulation was applied over the gastrocnemius muscle using a pneumatic tourniquet cuff, which was inflated to and maintained at a particular pressure. A computer-controlled air compressor maintained the pressure at a level that was individually tailored for each subject to produce an initial pain intensity rating of 40/100; cuff inflation was maintained for 120 seconds.

Mechanical Pain: Participants were assessed for mechanical pain by temporal summation, an analog of central sensitization, using weighted pinprick stimulators. The lowest-force stimulator that produced a sensation of discomfort was used to apply a train of 10 stimuli to the skin on the dorsum of the hand at the rate of 1 per second. Participants rated the painfulness of the first and 10th stimuli ${ }^{12}$. The same procedure was performed during the performance of a distraction task (sustained handgrip of a targeted grip force).$^{31}$

Cold-Induced Pain: Cold-induced pain was assessed using 3 trials of a cold-pressor task involving immersion of the right hand in a circulating cold water bath maintained at $4^{\circ} \mathrm{C}$. The first 2 tasks were immersions of the right hand for 30 seconds, with 2 minutes between immersions. During the first 2 cold pressor trials the conditioned pain modulation (CPM), a non-invasive test of endogenous pain-inhibitory systems, was assessed. The CPM Index is calculated using the formula: (PPTh during the cold pressor test/baseline PPTh)* $100 .{ }^{32}$ The final task involved immersion of the hand until the subject reached pain tolerance (or 3 minutes maximum). Participants rated the intensity of the cold pain on a 0 to 100 scale. Cold pain intensity ratings $(0-100)$ were also obtained 30 seconds after cold-pressor tests to assess painful after-sensation.

\section{Secondary Outcomes}

Depression Scores-Depression scores were assessed with the PHQ-9 questionnaire, a 9-item scale that evaluates the severity of depressive symptoms that is experienced within 
the previous two weeks. ${ }^{25}$ The PHQ-9 scores range from 0 to 27 , with depression severity being classified as minimal ( 1 to 4 ), mild (5 to 9), moderate (10 to 14 ), moderately severe (15 to 19$)$ or severe (20 to 27$){ }^{25}$

Health-Related Quality of life (QOL) — Health-Related QOL was assessed with the 36item Short-Form (SF-36) Health Survey which assesses eight domains: physical functioning, bodily pain, role limitations due to physical health problems, role limitations due to emotional problems, general health perceptions, mental health, social functioning and vitality. ${ }^{33}$ Each domain and the total score range from 0-100, with higher scores representing better QOL.

Pain Catastrophizing-Patients with chronic pain experience an array of negative cognitive and emotional processes which influence their perception of pain; otherwise known as pain catastrophizing. Pain catastrophizing is defined as a negative cognitiveaffective response to anticipated or actual pain. ${ }^{34}$ Catastrophizing is considered a significant risk factor for poor pain-related outcomes including increased pain severity, enhanced pain sensitivity and physical disability. ${ }^{35}$ Catastrophizing is measured by the validated Pain Catastrophizing Scale (PCS) which ask respondents to report the degree to which they tend to magnify the threat value of pain, feel helpless when in pain and their tendency to ruminate (inability to suppress pain-related thoughts) about pain. ${ }^{34,36}$ The PCS consists of 13 items that rate the degree to which subjects experience negative pain-related thoughts (scale of 0 to 4). These items assess rumination, magnification and helplessness domains. The scores of each domain are summed to generate the overall (composite) PCS score that ranges from 0 to $52 .{ }^{36}$

Anxiety Levels-Anxiety levels of the participants were assessed using the State-Trait Anxiety Inventory (STAI). The STAI consists of 40 items assessing state anxiety (anxiety level at the time of completion of the questionnaire) and trait anxiety (tendency to experience anxiety in stressful situations), with higher scores indicating greater levels of anxiety. ${ }^{37}$

\section{Laboratory Measurements}

Serum total testosterone was measured in a CLIA-certified laboratory using liquid chromatography-tandem mass spectrometry (LC-MS/MS) method with a sensitivity of 2 $\mathrm{ng} / \mathrm{dL}$. As inflammatory markers have been associated with pain perception, C-reactive protein (CRP) was measured using a high-sensitivity sandwich ELISA (Alpco Diagnostics, Salem, NH) with an intra-assay coefficient of variation (CV) of $5.6 \%$.

\section{Statistical Analysis}

The study was designed to insure, conservatively, $80 \%$ power to detect a twenty-four-week standardized difference between ADT and non-ADT arms of at least 0.5 in pain assessment, ignoring 6 and 12 week measurements, provided the baseline and 24 week measurements had intra-individual Pearson correlation of at least 0.5. This threshold was well-exceeded in practice, and use of all three follow-up measurements increased the information available for analysis. Tabular and graphical summaries were employed to assess empirical evidence in 
favor of differences between ADT and non-ADT arms at baseline and over time. Outcome trends with time were estimated using group- and time-specific means and $95 \%$ confidence intervals (CI). Mixed-effects regression was used to estimate group differences at baseline and follow-up (the latter was the average effect over the 24 weeks of intervention) using terms for group (ADT vs. non-ADT), time and the interaction between the two, and incorporating a random intercept at the participant level to acknowledge serial correlation. Statistical significance was evaluated using Walt-type tests of the hypothesis that the underlying interaction was zero. Given the number of QST measurements, the type I error rate (a) was set to 0.01 for the QST analyses; 0.05 was considered significant for all other outcomes.

\section{Results}

A total of 77 subjects ( 37 in the ADT group) enrolled in the study. The median age was 67 years (range 53 to 89 years) and the mean body mass index (BMI) was $28.3 \mathrm{~kg} / \mathrm{m}^{2}$ (range 21.9 to $37.7 \mathrm{~kg} / \mathrm{m}^{2}$ ). Serum total testosterone levels were normal in both groups at study entry. As expected, the Gleason score was higher in men about to receive ADT compared to the Non-ADT group; more participants in the ADT group received radiation treatment. Other baseline characteristics of participants allocated in the two groups are detailed in Table 1.

\section{Serum Testosterone Level}

ADT successfully suppressed testosterone production (mean $=13 \pm 8 \mathrm{ng} / \mathrm{dL}$ ) while testosterone levels did not change in the Non-ADT group (mean $=468 \pm 185 \mathrm{ng} / \mathrm{dL}$; Figure $1)$.

\section{Pain Perception and Pain Tolerance}

Clinical Pain-Change in mean total BPI score did not differ between the two groups (effect size $=0.31 ; 95 \% \mathrm{CI}=-0.55$ to $1.17 ; \mathrm{p}=0.48$; Figure $2 \mathrm{~A}$ ). Similarly, change in BPI severity subscore (effect size $=0.05 ; 95 \% \mathrm{CI}=-0.41$ to $0.50 ; \mathrm{p}=0.84$; Figure $2 \mathrm{~B}$ ) and BPI interference subscore (effect size $=0.26 ; 95 \% \mathrm{CI}=-0.25$ to $0.77 ; \mathrm{p}=0.31$; Figure $2 \mathrm{C}$ ) also did not differ between the two arms.

\section{Quantitative Sensory Testing (Experimental Pain)}

Pressure pain: Change in the initial ratings of prolonged pressure pain in the leg did not differ significantly between the two groups (effect size $=-1.12 ; 95 \% \mathrm{CI}=-3.99$ to $1.75 ; \mathrm{p}=$ 0.44 ; Figure 3A). Near-significant group differences were observed for leg pain ratings at 30 seconds (effect size $=-6.23 ; 95 \% \mathrm{CI}=-11.90$ to $-0.56 ; \mathrm{p}=0.031$; Figure $3 \mathrm{~B}$ ); however, this effect did not achieve frank significance. No significant or meaningful difference between groups was observed for PPTh at the thumb or trapezius (Supplementary Figure 1).

Mechanical Pain: Mechanical pain temporal summation did not significantly differ between groups (effect size $=-0.85 ; 95 \% \mathrm{CI}=-3.87$ to $2.16 ; \mathrm{p}=0.58$; Figure 3D). No difference was observed with the first (effect size $=-0.29 ; 95 \% \mathrm{CI}=-3.08$ to $2.49 ; \mathrm{p}=0.84$; Figure $3 \mathrm{E}$ ) and tenth (effect size $=-1.09 ; 95 \% \mathrm{CI}=-5.25$ to $3.06 ; \mathrm{p}=0.60$; Figure $3 \mathrm{~F}$ ) stimuli- 
generated pain ratings. Similar findings were evident for the temporal summation scores during the distraction trial (Figure 3G-I).

Cold Pain: There was no significant difference between groups for cold pain tolerance (effect size $=6.70 \mathrm{~s} ; 95 \% \mathrm{CI}=-9.19$ to $22.6 \mathrm{~s} ; \mathrm{p}=0.41 ;$ Figure 3J), and a trend toward lower CPM index scores in the ADT compared to the Non-ADT group did not achieve significance (effect size $=-9.52 ; 95 \% \mathrm{CI}=-20.29$ to $1.25 ; \mathrm{p}=0.08$; Figure $3 \mathrm{~K}$ ). No significant between-group differences were observed for cold pain at the 20 seconds or for cold pain after-sensations at 30 seconds (Supplementary Figure 1).

Pain Catastrophizing-Pain catastrophizing did not differ significantly between the groups (composite score; effect size $=-0.19 ; 95 \% \mathrm{CI}=-2.59$ to $2.21 ; \mathrm{p}=0.88$; Figure $4 \mathrm{~A}$ ). Sub-domains of helplessness (effect size $=0.33 ; 95 \% \mathrm{CI}=-0.77$ to $1.44 ; \mathrm{p}=0.55$; Figure 4B), magnification (effect size $=0.07 ; 95 \% \mathrm{CI}=-0.56$ to $0.69 ; \mathrm{p}=0.84$; Figure $4 \mathrm{C}$ ), and rumination (effect size $=-0.58 ; 95 \% \mathrm{CI}=-1.71$ to $0.55 ; \mathrm{p}=0.31$; Figure $4 \mathrm{D}$ ) also did not differ between the groups.

\section{C-Reactive Protein Concentration}

Mean serum concentrations of CRP did not differ significantly between the groups during the course of the study (effect size $=-0.50 ; 95 \% \mathrm{CI}=-1.63$ to $0.63 ; \mathrm{p}=0.38$; Figure 5).

\section{Depression and Quality of Life}

Depression scores on the PHQ-9 questionnaire significantly worsened in the ADT group compared to men in the Non-ADT group (effect size $=0.93 ; 95 \% \mathrm{CI}=0.04$ to $1.82 ; \mathrm{p}=$ 0.042; Figure 6A).

Men undergoing ADT showed a trend towards worsening in physical function compared to Non-ADT controls (effect size $=-5.35 ; 95 \% \mathrm{CI}=-11.04$ to $0.34 ; \mathrm{p}=0.06$; Figure $6 \mathrm{~B}$ ). Similarly, physical role limitation domain showed significant worsening in men receiving ADT (effect size $=-18.28 ; 95 \% \mathrm{CI}=-30.18$ to $-6.37 ; \mathrm{p}=0.003$; Figure $6 \mathrm{C}$ ). The emotional well-being (effect size $=-1.34 ; 95 \% \mathrm{CI}=-3.93$ to $1.16 ; \mathrm{p}=0.28$; Figure $6 \mathrm{D}$ ), emotional role limitation (effect size $=-6.31 ; 95 \% \mathrm{CI}=-16.07$ to $3.45 ; \mathrm{p}=0.20$; Figure $6 \mathrm{E}$ ), and energy (effect size $=-1.64 ; 95 \% \mathrm{CI}=-4.84$ to $1.56 ; \mathrm{p}=0.31$; Figure $6 \mathrm{~F}$ ) domains did not differ significantly between the two groups. Other QOL parameters also did not differ between the two arms (Supplementary Figure 1).

\section{Anxiety}

Men undergoing ADT displayed a trend towards worsening anxiety as assessed by STAI state scores (effect size $=2.34 ; 95 \% \mathrm{CI}=-0.09$ to $4.76 ; \mathrm{p}=0.059$; Figure 7A), while no change was seen in anxiety trait scores (effect size $=0.83 ; 95 \% \mathrm{CI}=-1.00$ to $2.67 ; \mathrm{p}=0.37$; Figure 7B). 


\section{Discussion}

A large body of evidence from animal and human studies suggests that testosterone has antinociceptive properties. ${ }^{4}$ Previous studies have shown that testosterone replacement in hypogonadal men with chronic pain improves pain tolerance. ${ }^{12,38}$ The clinical consequences of withdrawing testosterone on pain perception in men undergoing ADT for PCa had not been previously investigated. In this first systematic study, we show that ADT does not appear to affect mechanical or cold pain responses over 6 months of treatment. This finding contrasts with our previous observation that testosterone replacement does reduce some indices of mechanical pain sensitivity ${ }^{12}$. It is not clear why the present sample of ADT patients did not experience an increase in pain sensitivity, though it may be noteworthy that unlike our prior sample, ${ }^{12}$ these men were not experiencing chronic pain (the purpose of this study was to evaluate the direct role of androgen withdrawal on pain perception; therefore men with painful conditions were excluded). It is therefore conceivable that patients with existing chronic painful conditions who undergo ADT might experience worsening of their pain. It is also possible that the follow-up duration of 6 months during ADT might have been insufficient to observe changes in clinical or experimental pain. ${ }^{39-41}$

Worsening of depression scores is a concerning finding and is in agreement with previous reports. ${ }^{42,} 43$ Indeed, low endogenous testosterone concentrations have been associated with depressive symptoms, ${ }^{44,45}$ and testosterone replacement in hypogonadal men results in improvement in mood. ${ }^{46}$ Men in the ADT group also experienced worsening of physical function, in particular, role limitation due to physical health. Androgen deficiency as a result of ADT is associated with significant muscle atrophy and reduced muscle strength, which in turn leads to physical dysfunction. ${ }^{47}$ This is an important adverse effect as ADT-associated physical dysfunction increases predisposition to falls. ${ }^{48}$

Preclinical data suggests that testosterone has anxiolytic effects. ${ }^{49,}{ }^{50}$ Indeed, human studies confirm that hypogonadal men have higher anxiety levels, which is improved with testosterone replacement. ${ }^{51}$ However, evaluation of anxiety levels in men receiving ADT has not been evaluated systematically. In the present study, men undergoing ADT displayed greater anxiety scores compared to Non-ADT group. Future studies should evaluate mechanisms that lead to increased anxiety levels in men undergoing ADT.

The present study has several strengths: 1) the study had a prospective design that allowed to carefully follow changes in outcomes; 2 ) enrollment of eugonadal men provided a novel opportunity to determine the direct effect of testosterone suppression on pain perception and other outcomes; 3 ) serum testosterone was measured using liquid chromatography tandem mass spectrometry (the gold standard method); 4) none of the participants had existing painful conditions or bone metastasis, thus eliminating a major confounder; 5) all men received medical ADT with GnRH agonists and no one underwent orchiectomy, thus providing a homogenous sample; 6) enrollment of Non-ADT group as controls who were well-matched with the ADT group; and 7) validated instruments were used to assess patientimportant outcomes. The present work also has some limitations. We did not assess changes in heat pain, an important noxious stimulus. Furthermore, 6-month period of follow-up may not have been sufficient to observe pain outcomes. Lastly, we did not enroll (by design) men 
with existing painful conditions (including those with cancer-related pain); future studies should evaluate the impact of ADT on pain outcomes in men with prevalent pain.

In summary, ADT in men with PCa did not worsen clinical or experimental pain but was associated with worsening depression scores, anxiety levels and physical function-related QOL. These findings should guide both physicians and patients to make informed decisions regarding their treatment.

\section{Supplementary Material}

Refer to Web version on PubMed Central for supplementary material.

\section{Acknowledgments}

Funding: This study was supported by grant R21CA171316 (to SB and RRE) from the National Cancer Institute.

\section{References}

1. Unruh AM. Gender variations in clinical pain experience. Pain. 1996; 65:123-167. [PubMed: 8826503]

2. Sternbach RA. Pain and 'hassles' in the United States: findings of the Nuprin pain report. Pain. 1986; 27:69-80. [PubMed: 3785965]

3. Aloisi AM, Ceccarelli I, Fiorenzani P. Gonadectomy affects hormonal and behavioral responses to repetitive nociceptive stimulation in male rats. Ann N Y Acad Sci. 2003; 1007:232-237. [PubMed: 14993056]

4. Melchior M, Poisbeau P, Gaumond I, Marchand S. Insights into the mechanisms and the emergence of sex-differences in pain. Neuroscience. 2016; 338:63-80. [PubMed: 27180284]

5. El-Shormilisy N, Strong J, Meredith PJ. Associations between gender, coping patterns and functioning for individuals with chronic pain: a systematic review. Pain Res Manag. 2015; 20:4855. [PubMed: 24927488]

6. Paller CJ, Campbell CM, Edwards RR, Dobs AS. Sex-based differences in pain perception and treatment. Pain Med. 2009; 10:289-299. [PubMed: 19207233]

7. Fillingim RB, Edwards RR, Powell T. The relationship of sex and clinical pain to experimental pain responses. Pain. 1999; 83:419-425. [PubMed: 10568849]

8. Berkley KJ, Zalcman SS, Simon VR. Sex and gender differences in pain and inflammation: a rapidly maturing field. Am J Physiol Regul Integr Comp Physiol. 2006; 291:R241-244. [PubMed: 16675636]

9. Racine M, Tousignant-Laflamme Y, Kloda LA, Dion D, Dupuis G, Choiniere M. A systematic literature review of 10 years of research on sex/gender and experimental pain perception - part 1: are there really differences between women and men? Pain. 2012; 153:602-618. [PubMed: 22192712]

10. Zubieta JK, Smith YR, Bueller JA, et al. mu-opioid receptor-mediated antinociceptive responses differ in men and women. J Neurosci. 2002; 22:5100-5107. [PubMed: 12077205]

11. Vincent K, Warnaby C, Stagg CJ, Moore J, Kennedy S, Tracey I. Brain imaging reveals that engagement of descending inhibitory pain pathways in healthy women in a low endogenous estradiol state varies with testosterone. Pain. 2013; 154:515-524. [PubMed: 23318125]

12. Basaria S, Travison TG, Alford D, et al. Effects of testosterone replacement in men with opioidinduced androgen deficiency: a randomized controlled trial. Pain. 2015; 156:280-288. [PubMed: 25599449]

13. Siegel RL, Miller KD, Jemal A. Cancer statistics, 2017. CA Cancer J Clin. 2017; 67:7-30. [PubMed: 28055103]

14. Dy GW, Gore JL, Forouzanfar MH, Naghavi M, Fitzmaurice C. Global Burden of Urologic Cancers, 1990-2013. Eur Urol. 2017; 71:437-446. [PubMed: 28029399] 
15. Huggins C, Hodges CV. Studies on prostatic cancer. I. The effect of castration, of estrogen and androgen injection on serum phosphatases in metastatic carcinoma of the prostate. CA Cancer $\mathbf{J}$ Clin. 1972; 22:232-240. [PubMed: 4625049]

16. Jones CU, Hunt D, McGowan DG, et al. Radiotherapy and short-term androgen deprivation for localized prostate cancer. N Engl J Med. 2011; 365:107-118. [PubMed: 21751904]

17. Bolla M, Collette L, Blank L, et al. Long-term results with immediate androgen suppression and external irradiation in patients with locally advanced prostate cancer (an EORTC study): a phase III randomised trial. Lancet. 2002; 360:103-106. [PubMed: 12126818]

18. Bubley GJ, Carducci M, Dahut W, et al. Eligibility and response guidelines for phase II clinical trials in androgen-independent prostate cancer: recommendations from the Prostate-Specific Antigen Working Group. J Clin Oncol. 1999; 17:3461-3467. [PubMed: 10550143]

19. van Andel G, Kurth KH. The impact of androgen deprivation therapy on health related quality of life in asymptomatic men with lymph node positive prostate cancer. Eur Urol. 2003; 44:209-214. [PubMed: 12875940]

20. Basaria S. Androgen deprivation therapy, insulin resistance, and cardiovascular mortality: an inconvenient truth. J Androl. 2008; 29:534-539. [PubMed: 18567642]

21. Shahani S, Braga-Basaria M, Basaria S. Androgen deprivation therapy in prostate cancer and metabolic risk for atherosclerosis. J Clin Endocrinol Metab. 2008; 93:2042-2049. [PubMed: 18349064]

22. van den Beuken-van Everdingen MH, de Rijke JM, Kessels AG, Schouten HC, van Kleef M, Patijn J. Prevalence of pain in patients with cancer: a systematic review of the past 40 years. Ann Oncol. 2007; 18:1437-1449. [PubMed: 17355955]

23. Gerbershagen HJ, Ozgur E, Straub K, et al. Prevalence, severity, and chronicity of pain and general health-related quality of life in patients with localized prostate cancer. Eur J Pain. 2008; 12:339350. [PubMed: 17855135]

24. Sandblom G, Carlsson P, Sennfalt K, Varenhorst E. A population-based study of pain and quality of life during the year before death in men with prostate cancer. Br J Cancer. 2004; 90:1163-1168. [PubMed: 15026796]

25. Kroenke K, Spitzer RL, Williams JB. The PHQ-9: validity of a brief depression severity measure. J Gen Intern Med. 2001; 16:606-613. [PubMed: 11556941]

26. Tan G, Jensen MP, Thornby JI, Shanti BF. Validation of the Brief Pain Inventory for chronic nonmalignant pain. J Pain. 2004; 5:133-137. [PubMed: 15042521]

27. Cleeland CS, Ryan KM. Pain assessment: global use of the Brief Pain Inventory. Ann Acad Med Singapore. 1994; 23:129-138. [PubMed: 8080219]

28. Shi Q, Mendoza TR, Dueck AC, et al. Determination of mild, moderate, and severe pain interference in patients with cancer. Pain. 2017

29. Arendt-Nielsen L, Yarnitsky D. Experimental and clinical applications of quantitative sensory testing applied to skin, muscles and viscera. J Pain. 2009; 10:556-572. [PubMed: 19380256]

30. Graven-Nielsen T, Arendt-Nielsen L. Assessment of mechanisms in localized and widespread musculoskeletal pain. Nat Rev Rheumatol. 2010; 6:599-606. [PubMed: 20664523]

31. Schreiber KL, Campbell C, Martel MO, et al. Distraction analgesia in chronic pain patients: the impact of catastrophizing. Anesthesiology. 2014; 121:1292-1301. [PubMed: 25264596]

32. Edwards RR, Dolman AJ, Michna E, et al. Changes in Pain Sensitivity and Pain Modulation During Oral Opioid Treatment: The Impact of Negative Affect. Pain Med. 2016; 17:1882-1891. [PubMed: 26933094]

33. Ware JE Jr, Sherbourne CD. The MOS 36-item short-form health survey (SF-36). I. Conceptual framework and item selection. Med Care. 1992; 30:473-483. [PubMed: 1593914]

34. Quartana PJ, Campbell CM, Edwards RR. Pain catastrophizing: a critical review. Expert Rev Neurother. 2009; 9:745-758. [PubMed: 19402782]

35. Edwards RR, Cahalan C, Mensing G, Smith M, Haythornthwaite JA. Pain, catastrophizing, and depression in the rheumatic diseases. Nat Rev Rheumatol. 2011; 7:216-224. [PubMed: 21283147]

36. Osman A, Barrios FX, Kopper BA, Hauptmann W, Jones J, O’Neill E. Factor structure, reliability, and validity of the Pain Catastrophizing Scale. J Behav Med. 1997; 20:589-605. [PubMed: 9429990] 
37. Spielberger, CD. State-Trait Anxiety Inventory: A Comprehensive Bibliography. Palo Alto, CA: Consulting Psychologists Press; 1989.

38. Daniell HW, Lentz R, Mazer NA. Open-label pilot study of testosterone patch therapy in men with opioid-induced androgen deficiency. J Pain. 2006; 7:200-210. [PubMed: 16516826]

39. Granot M, Lowenstein L, Yarnitsky D, Tamir A, Zimmer EZ. Postcesarean section pain prediction by preoperative experimental pain assessment. Anesthesiology. 2003; 98:1422-1426. [PubMed: 12766652]

40. Hsu YW, Somma J, Hung YC, Tsai PS, Yang CH, Chen CC. Predicting postoperative pain by preoperative pressure pain assessment. Anesthesiology. 2005; 103:613-618. [PubMed: 16129988]

41. Yarnitsky D, Crispel Y, Eisenberg E, et al. Prediction of chronic post-operative pain: pre-operative DNIC testing identifies patients at risk. Pain. 2008; 138:22-28. [PubMed: 18079062]

42. Dinh KT, Reznor G, Muralidhar V, et al. Association of Androgen Deprivation Therapy With Depression in Localized Prostate Cancer. J Clin Oncol. 2016; 34:1905-1912. [PubMed: 27069075]

43. Chung SD, Kao LT, Lin HC, Xirasagar S, Huang CC, Lee HC. Patients receiving androgen deprivation therapy for prostate cancer have an increased risk of depressive disorder. PLoS One. 2017; 12:e0173266. [PubMed: 28253340]

44. Zarrouf FA, Artz S, Griffith J, Sirbu C, Kommor M. Testosterone and depression: systematic review and meta-analysis. J Psychiatr Pract. 2009; 15:289-305. [PubMed: 19625884]

45. Wainwright SR, Lieblich SE, Galea LA. Hypogonadism predisposes males to the development of behavioural and neuroplastic depressive phenotypes. Psychoneuroendocrinology. 2011; 36:13271341. [PubMed: 21481538]

46. Snyder PJ, Bhasin S, Cunningham GR, et al. Effects of Testosterone Treatment in Older Men. N Engl J Med. 2016; 374:611-624. [PubMed: 26886521]

47. Nguyen PL, Alibhai SM, Basaria S, et al. Adverse effects of androgen deprivation therapy and strategies to mitigate them. Eur Urol. 2015; 67:825-836. [PubMed: 25097095]

48. Bylow K, Dale W, Mustian K, et al. Falls and physical performance deficits in older patients with prostate cancer undergoing androgen deprivation therapy. Urology. 2008; 72:422-427. [PubMed: 18561991]

49. Carrier N, Saland SK, Duclot F, He H, Mercer R, Kabbaj M. The Anxiolytic and Antidepressantlike Effects of Testosterone and Estrogen in Gonadectomized Male Rats. Biol Psychiatry. 2015; 78:259-269. [PubMed: 25683735]

50. Aikey JL, Nyby JG, Anmuth DM, James PJ. Testosterone rapidly reduces anxiety in male house mice (Mus musculus). Horm Behav. 2002; 42:448-460. [PubMed: 12488111]

51. Aydogan U, Aydogdu A, Akbulut H, et al. Increased frequency of anxiety, depression, quality of life and sexual life in young hypogonadotropic hypogonadal males and impacts of testosterone replacement therapy on these conditions. Endocr J. 2012; 59:1099-1105. [PubMed: 22972022] 


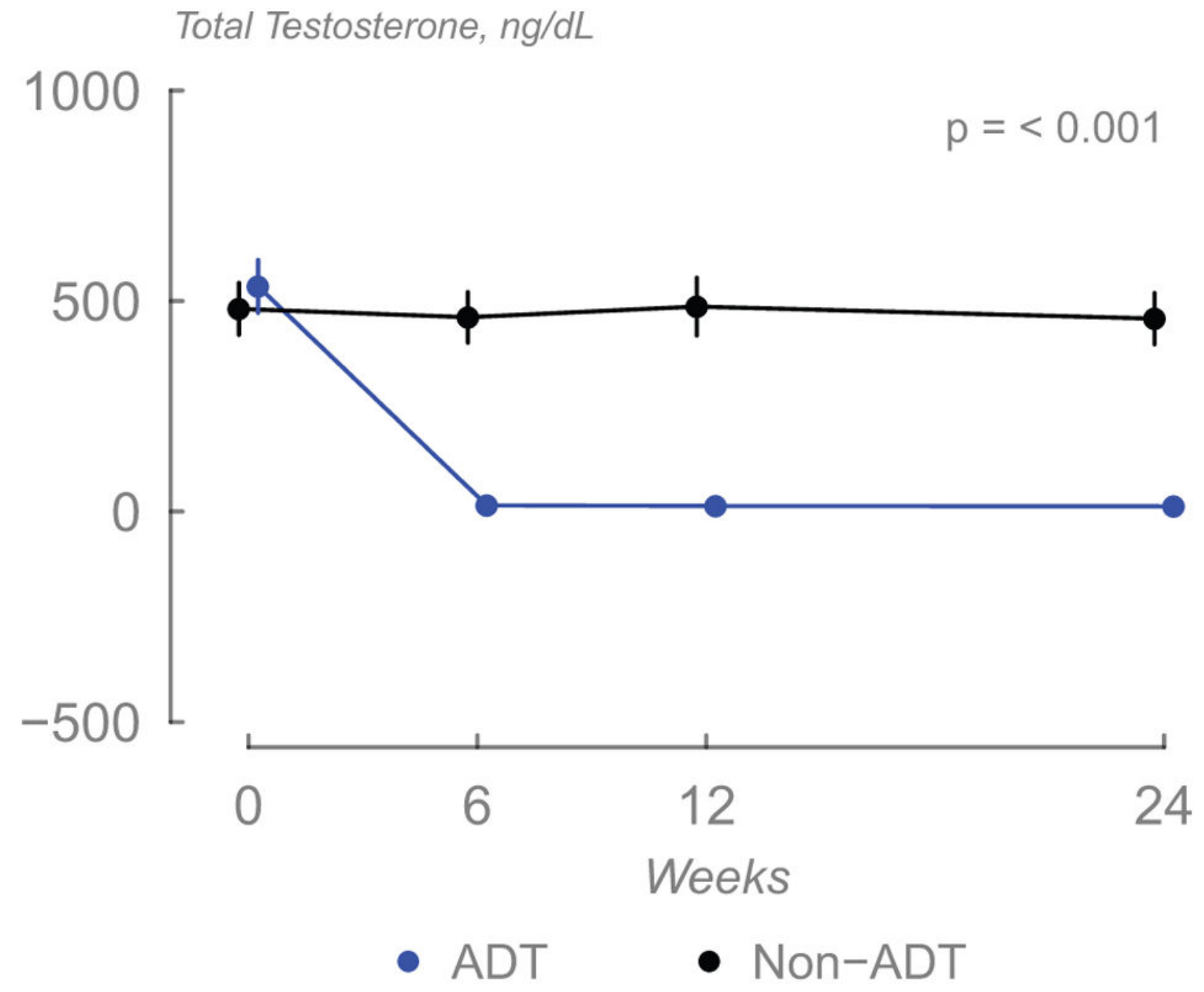

Figure 1.

Changes in serum total testosterone levels in both groups. Data displayed as means; error bars are $95 \% \mathrm{CI}$. 
A BPI, Total
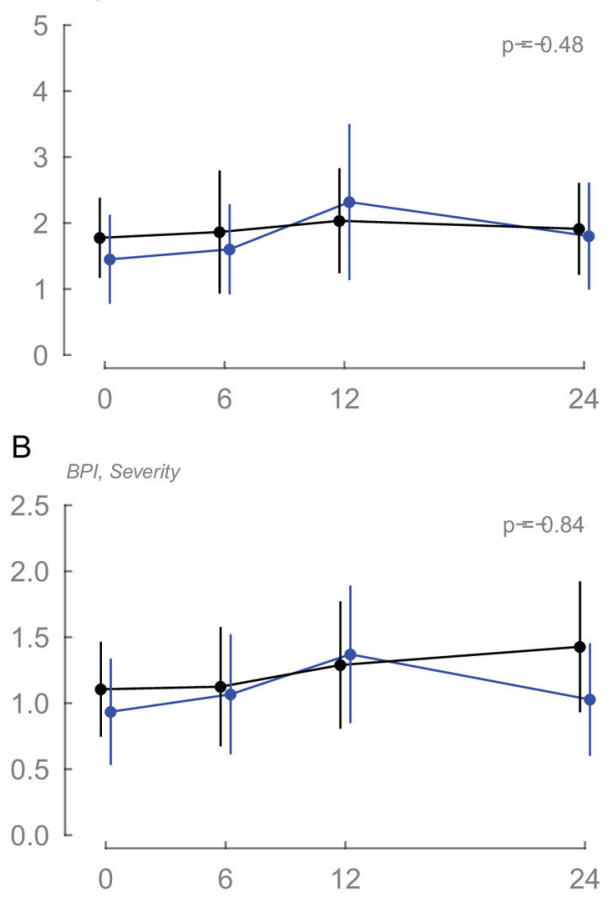

C BPI, Interference

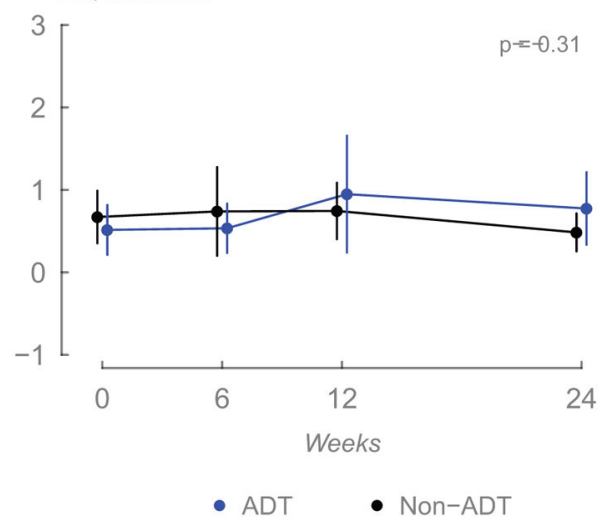

Figure 2.

Changes in (A) total BPI, (B) BPI severity and (C) BPI interference scores during the study. Data displayed as means; error bars are $95 \% \mathrm{CI}$. 

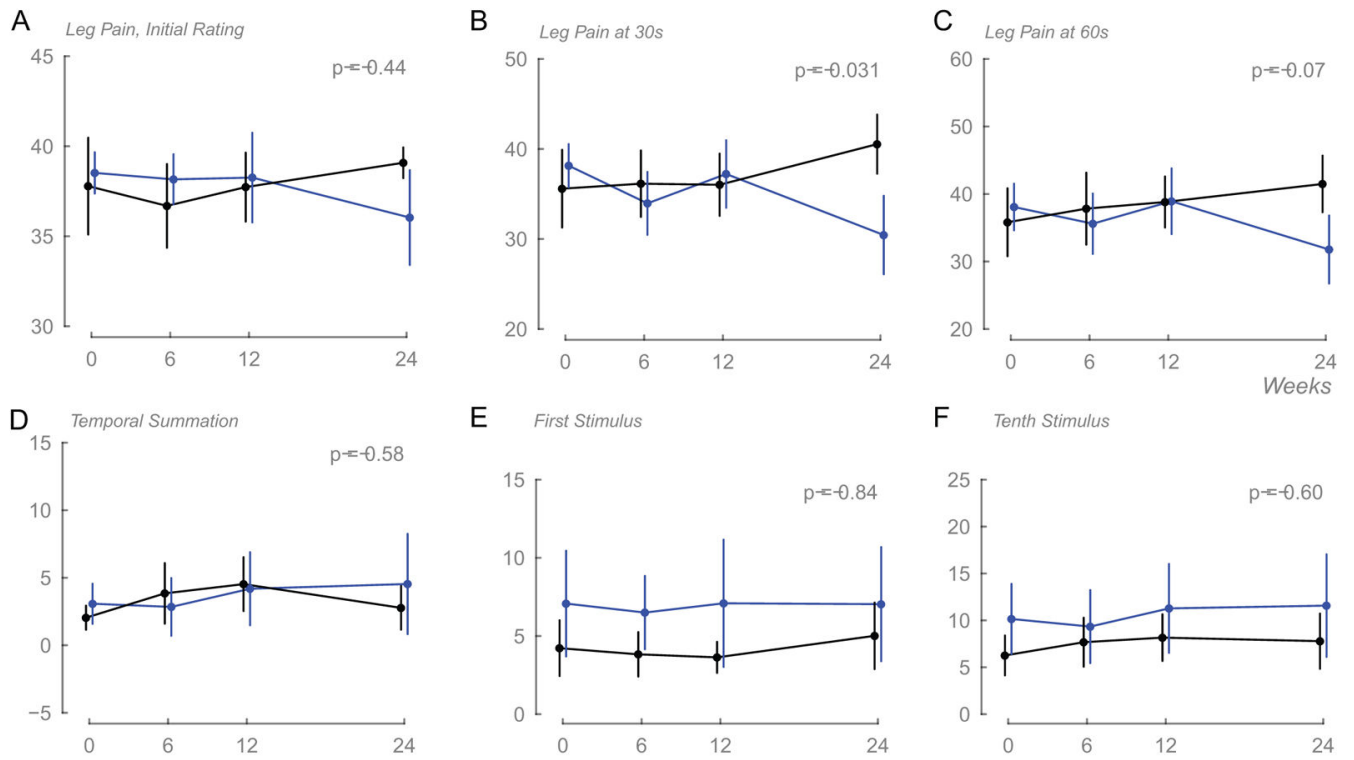

F Tenth Stimulus
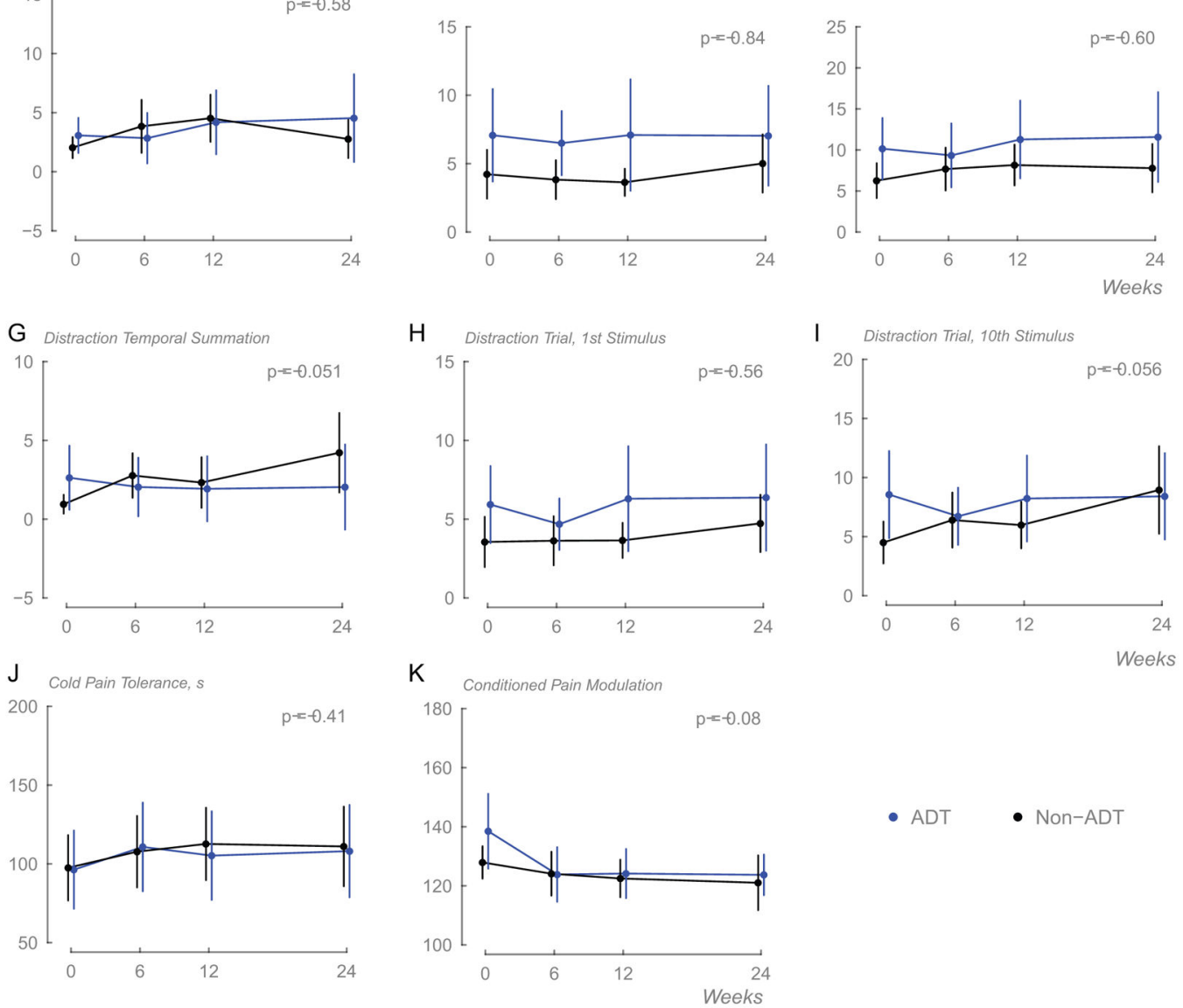

Figure 3.

Changes in (A) initial rating of pain, (B) prolonged pressure pain at 30 seconds, (C) prolonged pressure pain at 60 seconds, (D) mechanical pain temporal summation, (E) pain score with first stimulus, $(F)$ pain score with tenth stimulus, $(G)$ mechanical pain temporal summation in the distraction trial, $(\mathrm{H})$ pain score with first stimulus in the distraction trial, (I) pain score with tenth stimulus in the distraction trial; $(\mathrm{J})$ cold pain tolerance, and $(\mathrm{L})$ CPM index in each group. Data displayed as means; error bars are 95\% CI. CPM, conditioned pain modulation.

J Pain Symptom Manage. Author manuscript; available in PMC 2019 February 01. 
A PCS, Composite

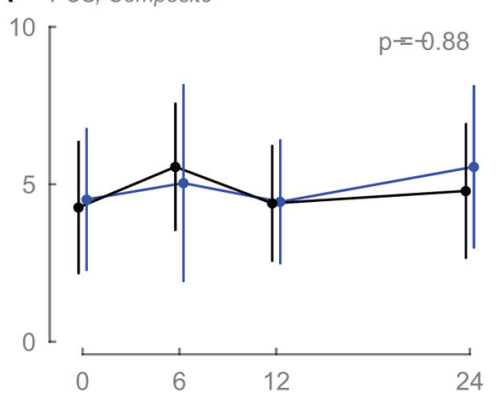

C

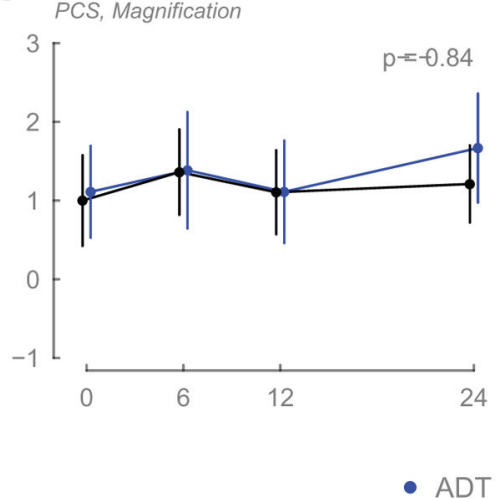

B PCS, Helplessness

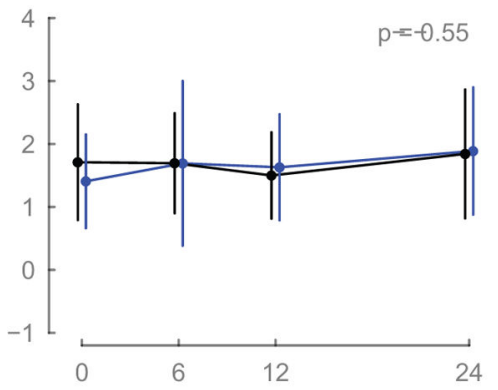

$\mathrm{D}$

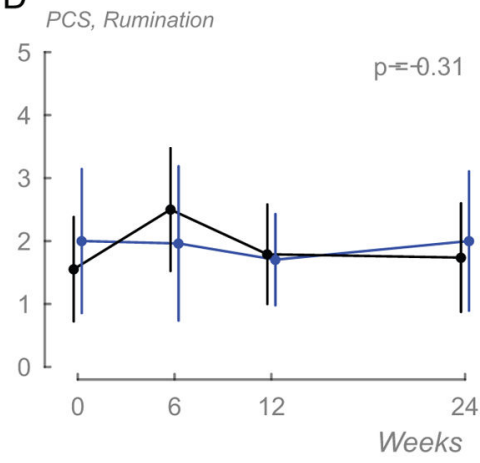

- Non-ADT

Figure 4.

Changes in (A) composite scores of pain catastrophizing, and (B) helplessness, (C) magnification and (D) rumination subdomain scores in each group. Data displayed as means; error bars are $95 \% \mathrm{CI}$. 
C-Reactive Protein, $\mathrm{mg} / \mathrm{dl}$

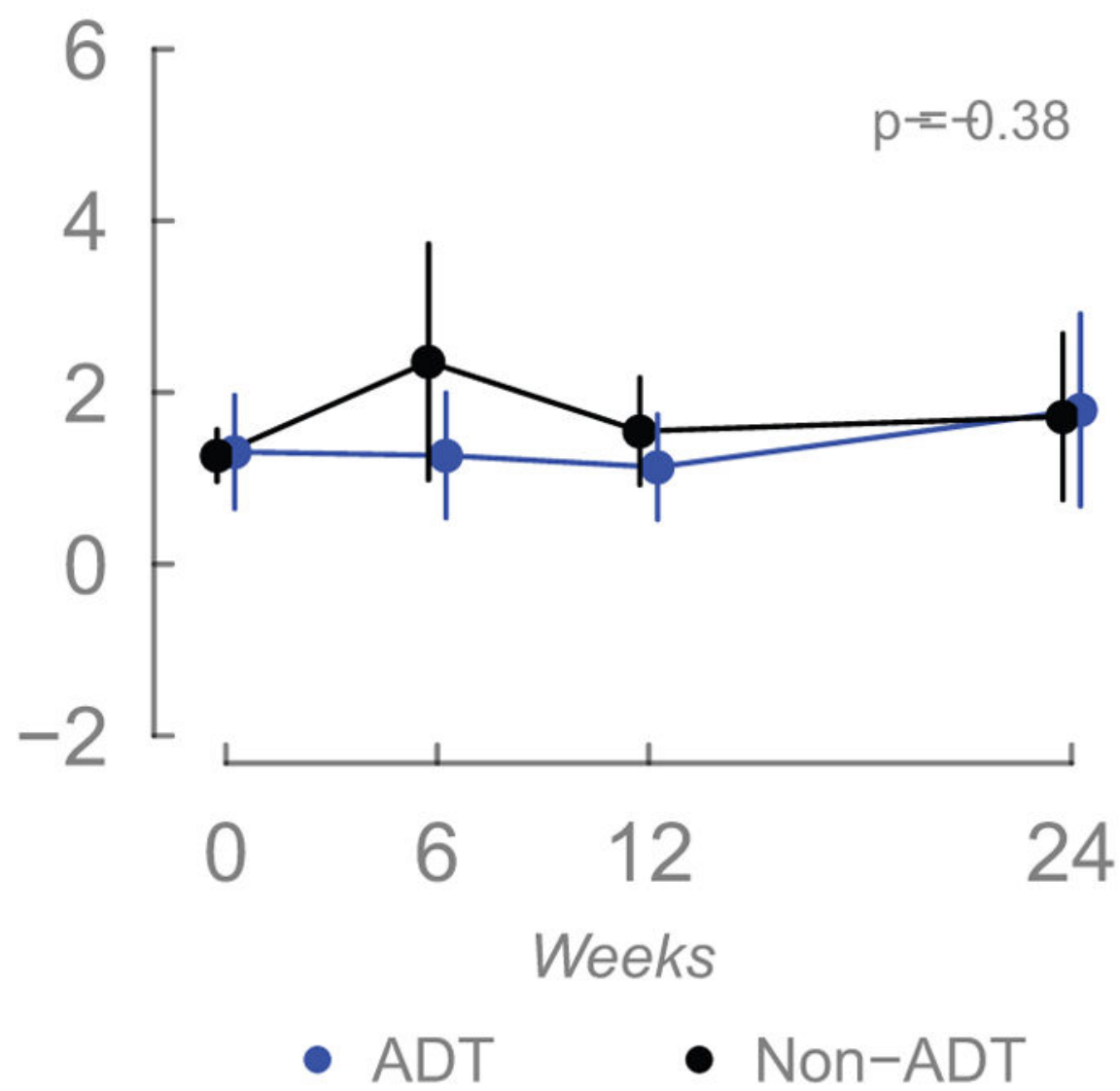

Figure 5.

Changes in C-reactive protein concentrations in each group during the course of the study. Data displayed as means; error bars are $95 \%$ CI. 


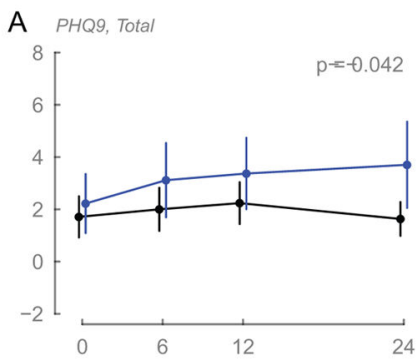

B
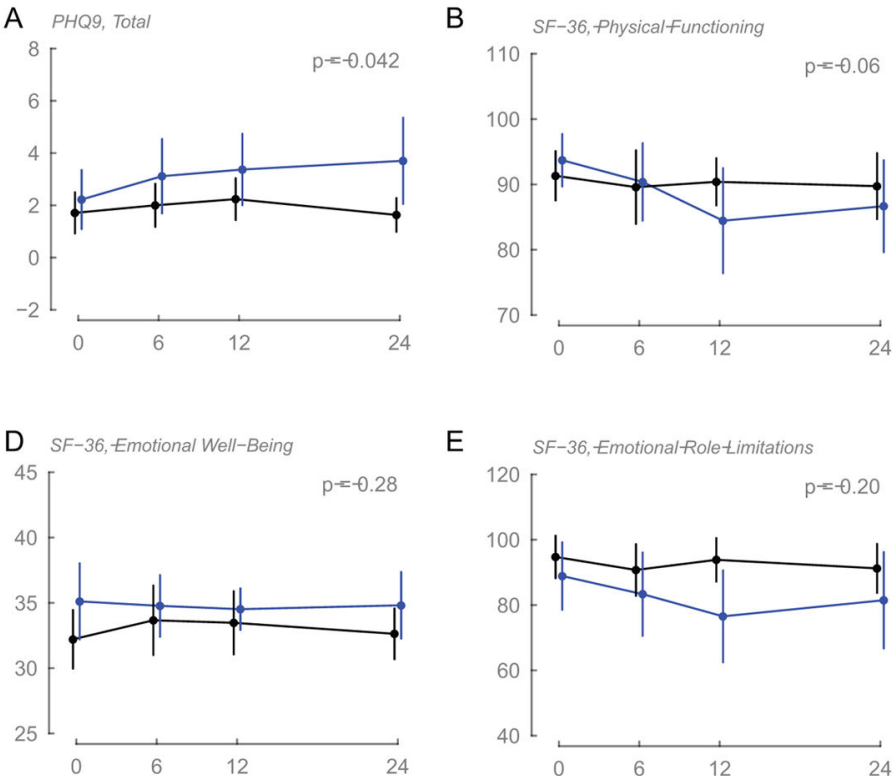

E

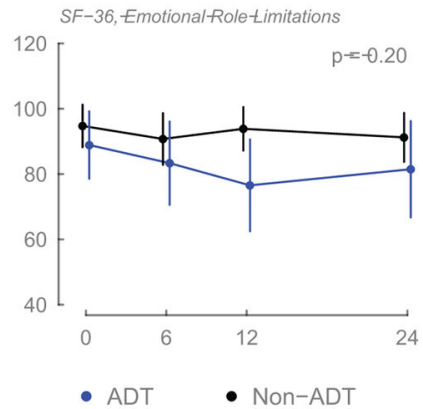

C SF-36, PhysicalRoletimitations

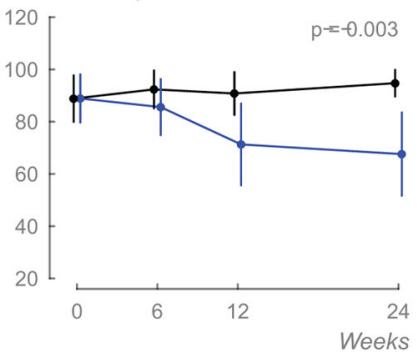

F SF-36,Energy

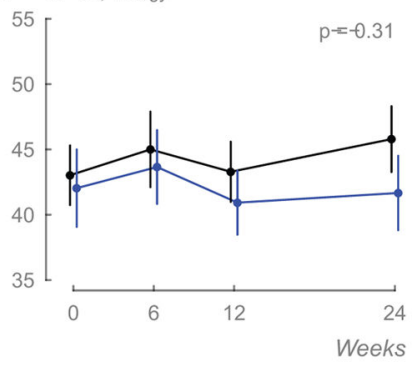

Figure 6.

Changes in (A) depression scores on PHQ-9 questionnaire, (B) physical functioning domain on SF-36 questionnaire, (C) physical role limitations domain on SF-36, and (D) emotional well-being on SF-36 in each group. Data displayed as means; error bars are 95\% CI. 

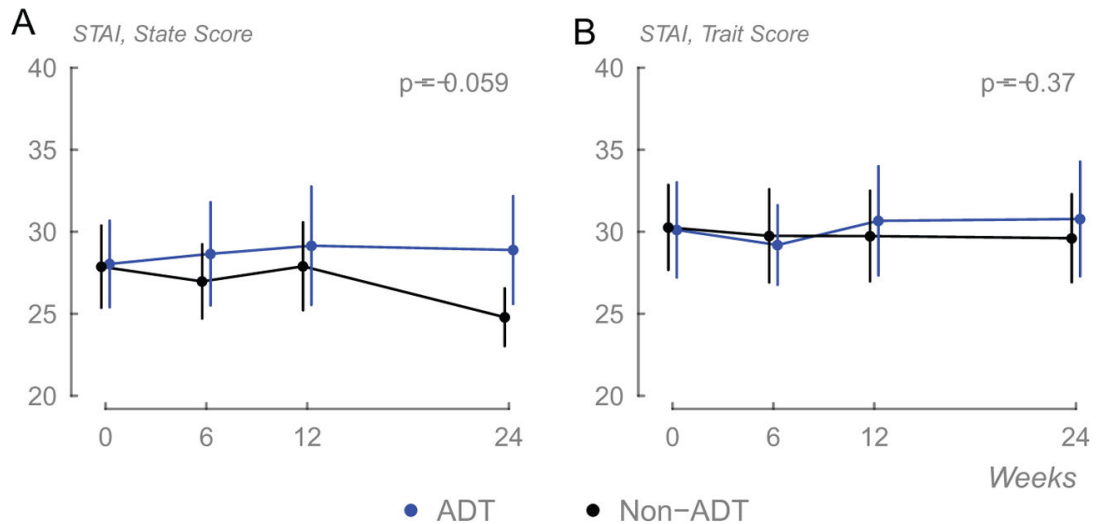

Figure 7.

Changes in (A) STAI-state and (B) STAI-trait scores in each group. Data displayed as means; error bars are $95 \% \mathrm{CI}$. 


\section{Table 1}

Baseline characteristics of participants in each group.

\begin{tabular}{|c|c|c|}
\hline & Non-ADT & ADT \\
\hline & $\mathrm{n}=\mathbf{4 0}$ & $\mathbf{n}=\mathbf{3 7}$ \\
\hline \multicolumn{3}{|l|}{ Demographics } \\
\hline Age (years) & $66 \pm 7$ & $67 \pm 8$ \\
\hline $\operatorname{BMI}\left(\mathrm{kg} / \mathrm{m}^{2}\right)$ & $28.1 \pm 3.5$ & $28.5 \pm 3.8$ \\
\hline \multicolumn{3}{|l|}{ Race } \\
\hline \multicolumn{3}{|l|}{ Laboratory Parameters } \\
\hline Total Testosterone & $481 \pm 193$ & $534 \pm 189$ \\
\hline CRP & $1.4 \pm 1.2$ & $1.4 \pm 1.7$ \\
\hline \multicolumn{3}{|l|}{ Prostate Cancer History } \\
\hline Prostatectomy (\%) & 95.0 & 73.0 \\
\hline Radiation (\%) & 5.0 & 56.8 \\
\hline Gleason Score & $6.6 \pm 1.1$ & $7.4 \pm 0.9$ \\
\hline \multicolumn{3}{|l|}{ Medications } \\
\hline Antidepressants (\%) & 15.0 & 13.5 \\
\hline \multicolumn{3}{|l|}{ Clinical Pain } \\
\hline BPI: Total & $1.84 \pm 1.78$ & $1.77 \pm 2.18$ \\
\hline BPI: Severity & $1.17 \pm 1.08$ & $1.18 \pm 1.33$ \\
\hline BPI: Interference & $0.67 \pm 0.95$ & $0.58 \pm 0.94$ \\
\hline \multicolumn{3}{|l|}{ Experimental Pain (QST) } \\
\hline \multicolumn{3}{|l|}{ Pressure Pain } \\
\hline Pressure Pain Threshold: Trapezius (kPa) & $499.3 \pm 191.6$ & $638.1 \pm 159.5$ \\
\hline Pressure Pain Threshold: Thumb (kPa) & $325.4 \pm 115.8$ & $373.2 \pm 107.5$ \\
\hline Prolonged Pressure Pain - initial rating & $37.9 \pm 7.9$ & $38.1 \pm 2.9$ \\
\hline Prolonged Pressure Pain at 30s & $35.8 \pm 12.7$ & $37.8 \pm 5.7$ \\
\hline Prolonged Pressure Pain at 60s & $35.8 \pm 14.7$ & $38.4 \pm 8.3$ \\
\hline \multicolumn{3}{|l|}{ Mechanical Pain } \\
\hline Mechanical Probe Pain: $1^{\text {st }}$ stimulus & $4.2 \pm 5.3$ & $7.0 \pm 8.5$ \\
\hline Mechanical Probe Pain: $10^{\text {th }}$ stimulus & $6.3 \pm 6.3$ & $9.5 \pm 9.3$ \\
\hline Temporal Summation & $2.1 \pm 2.6$ & $2.5 \pm 3.5$ \\
\hline Mechanical Probe pain: $1^{\text {st }}$ stimulus - Distraction trial & $3.5 \pm 4.7$ & $5,4 \pm 5.8$ \\
\hline Mechanical Probe pain: $10^{\text {th }}$ stimulus - Distraction trial & $4.5 \pm 5.2$ & $7.4 \pm 8.5$ \\
\hline Temporal Summation - Distraction trial & $1.0 \pm 1.8$ & $1.9 \pm 4.7$ \\
\hline \multicolumn{3}{|l|}{ Cold Pain } \\
\hline Cold Pain at 20s & $59 \pm 26$ & $60 \pm 25$ \\
\hline Maximum Cold Pain & $71 \pm 24$ & $72 \pm 23$ \\
\hline Cold Pain Tolerance (s) & $95 \pm 60$ & $101 \pm 66$ \\
\hline
\end{tabular}

J Pain Symptom Manage. Author manuscript; available in PMC 2019 February 01. 


\begin{tabular}{|c|c|c|}
\hline & Non-ADT & ADT \\
\hline & $\mathrm{n}=\mathbf{4 0}$ & $\mathbf{n}=\mathbf{3 7}$ \\
\hline Cold Pain Aftersensation at 30s & $8.3 \pm 10.7$ & $13.6 \pm 11.8$ \\
\hline Conditioned Pain Modulation Index & $129.4 \pm 16.6$ & $134.9 \pm 25.2$ \\
\hline \multicolumn{3}{|l|}{ Pain Catastrophizing Scale (PCS) } \\
\hline Composite Score & $4.25 \pm 6.19$ & $5.49 \pm 7.26$ \\
\hline Rumination Score & $1.5 \pm 2.47$ & $2.35 \pm 3.28$ \\
\hline Magnification Score & $1.03 \pm 1.72$ & $1.24 \pm 1.67$ \\
\hline Helplessness Score & $1.73 \pm 2.73$ & $1.89 \pm 2.90$ \\
\hline \multicolumn{3}{|l|}{ Patient Health Questionnaire (PHQ-9) } \\
\hline Total Score & $1.75 \pm 2.36$ & $2.38 \pm 2.67$ \\
\hline \multicolumn{3}{|l|}{ Quality of Life: Short Form-36 (SF-36) } \\
\hline \multicolumn{3}{|l|}{ Physical Domains } \\
\hline Physical Function & $91.25 \pm 11.19$ & $87.16 \pm 19.70$ \\
\hline Bodily Pain & $83.94 \pm 16.17$ & $84.80 \pm 14.24$ \\
\hline Role Limitations due to Physical Health Problems & $89.38 \pm 26.49$ & $87.16 \pm 24.74$ \\
\hline \multicolumn{3}{|l|}{ Mental Domains } \\
\hline Role Limitations due to Personal or Emotional Problems & $95.00 \pm 19.32$ & $87.39 \pm 27.61$ \\
\hline Emotional Well-being & $32.30 \pm 6.68$ & $35.14 \pm 8.28$ \\
\hline Social Functioning & $95.00 \pm 11.94$ & $88.85 \pm 17.62$ \\
\hline Energy/Fatigue & $42.75 \pm 7.42$ & $41.76 \pm 8.10$ \\
\hline General Health Perceptions & $57.13 \pm 8.46$ & $56.35 \pm 9.48$ \\
\hline \multicolumn{3}{|l|}{ State-Trait Anxiety Inventory (STAI) } \\
\hline State Score & $27.78 \pm 7.43$ & $29.05 \pm 7.29$ \\
\hline Trait Score & $30.13 \pm 7.71$ & $30.78 \pm 7.57$ \\
\hline
\end{tabular}

Data are expressed as mean \pm SD. BPI, brief pain inventory questionnaire; QST, quantitative sensory testing. 